Article

\title{
Application of Acoustic Emission Technique to the Evaluation of Coal Seam Hydraulic Flushing Effect
}

\author{
Rongxi Shen ${ }^{1,2}$, Xuan Zhang ${ }^{1,2, *} \mathbb{0}$, Enyuan Wang ${ }^{1,2}$, Hongru Li ${ }^{1,2}$, Xu Han ${ }^{1,2}$ and \\ Zhenhai Hou ${ }^{1,2}$ \\ 1 Key Laboratory of Gas and Fire Control for Coal Mines, China University of Mining and Technology, \\ Xuzhou 221116, China; shenrongxi@126.com (R.S.); weytop@cumt.edu.cn (E.W.); \\ lihongrucumt@126.com (H.L.); hanxua1219@163.com (X.H.); HZH074014@163.com (Z.H.) \\ 2 School of Safety Engineering, China University of Mining and Technology, Xuzhou 221116, China \\ * Correspondence: zhangxuan_up@163.com; Tel.: +86-1370-521-5853
}

Received: 18 March 2019; Accepted: 30 April 2019; Published: 6 May 2019

\begin{abstract}
Hydraulic flushing has the advantages of reducing coal stress and improving coal seam permeability, so it is widely used in high gas outburst coal seams in China. However, the effect evaluation of stress relief and permeability enhancement will be necessary before coal mining. In this paper, an acoustic emission (AE) experiment system of coal seam hydraulic flushing was established, and the $\mathrm{AE}$ characteristics of coal during hydraulic flushing were studied. The results show that the changes in AE signals are basically consistent with those in load and water pressure. In addition, the quantitative relationship between the signals and the damage of coal around the borehole is revealed by the theory of damage mechanics. The in-situ AE test of hydraulic flushing was performed in the Liangbei Coal Mine, by measuring gas flow and coal stress simultaneously. The variation of $\mathrm{AE}$ activities and the effect evaluation of hydraulic flushing were analyzed. The results reveal that the changes in coal seam stress are basically consistent with those of AE signals. After the flushing has been completed for $1-3 \mathrm{~h}$, the coal seam stress decreases rapidly, and the AE counts and intensity reach the peak. Therefore, this study proposes a new method for evaluating the effect of coal seam hydraulic flushing by $\mathrm{AE}$, which has a very important practical significance.
\end{abstract}

Keywords: acoustic emission; hydraulic flushing; effect evaluation

\section{Introduction}

With the shallow coal resources exhausting, China's coal mining depth continues to increase at a rate of about $20 \mathrm{~m}$ per year, and the impact of ground stress increases accordingly. Due to the complicated geological structure of the mine in China, the permeability of the coal seam is about three orders of magnitude lower than that of America on average, resulting in high gas content and high gas pressure in the coal seam. These reasons lead to more and more serious coal and rock dynamic disasters in the mining process. Coal and gas outburst accidents not only damage the underground facilities and cause casualties, but also may seriously threaten the buildings on the ground [1]. Therefore, the research on safe mining of outburst-prone coal seams is of great significance for safe and efficient mining in coal mines. Over $95 \%$ of high gas content and outburst-prone coal seams in China have low permeability [2-4], with a permeability coefficient of generally lower than $0.1 \mathrm{~m}^{2} / \mathrm{MPa}^{2} \mathrm{~d}$ [5]. In recent years, experts and scholars have conducted much research on the prevention and control of coal and gas outburst disasters. With an in-depth study on the mechanism, and laws and prevention methods of the disasters, a complete technical system for prevention and control of the disasters has been formed in China. In the system, hydraulic flushing for pressure relief and permeability enhancement in coal seams is one of the mature and widely used measures to reduce outbursts. 
The mechanism of the hydraulic flushing technique is to discharge crushed coal and gas by the impact of a high-pressure water jet, and change the stress field around the bore hole to achieve local pressure relief, so as to lower gas pressure, improve coal seam structure and permeability, and effectively reduce the coal seam gas content. In addition, the coal body around the bore hole can be wetted to improve its plasticity and reduce its elasticity [6]. Bo [6] combined flow and gas measurements to determine the pressure relief range of gas drainage boreholes, which had determined the pressure relief range of a gas drainage borehole. The results obtained by different methods are basically consistent, and the pressure relief radius is between $7.6-8.0 \mathrm{~m}$. The research results can help optimize the borehole layout parameters. Lin et al. [7] improved the hydraulic flushing drill bit and proposed a dual-power drilling technique, which greatly improved the drilling speed and pressure relief effect. Hao [8] proposed a new technique of gas extraction through coal seam hydraulic flushing (ISBHF). In this study, the flow characteristics of borehole gas were simulated by COMSOL software first, and then the simulation results were verified by field experiments. Kong [9] established a model of two-dimensional gas seepage to study the coupling effects of borehole radius, initial gas pressure and coal seam permeability on the effective radius of hydraulic flushing. The research results are conducive to selecting the appropriate radius of borehole and promoting the efficiency of gas extraction. Zhao [10] analyzed the effects of characteristic parameters such as the initial diffusion coefficient, the diffusion attenuation coefficient and the initial gas pressure on the content of gas extracted through hydraulic grooving drilling. After analyzing the effects of physical properties of coal seam on hydraulic flushing borehole enlargement and mine gas drainage, $\mathrm{Li}$ [11] proposed a new method to raise gas drainage through hydraulic borehole enlargement. Previous studies mostly focused on the determination of drill bit and borehole parameters in the process of hydraulic flushing and the improvement of flushing technique. There are few studies on the test method of pressure relief effect after hydraulic flushing. Qiu [5] proposed to reflect the pressure relief range and pressure relief effect of hydraulic flushing by measuring the variation of resistivity of coal body before and after hydraulic flushing. The mechanism of measuring the pressure relief effect of hydraulic flushing is based on the difference in the conductivity of coal and rock before and after the failure. First, a stable electric current is provided to the experimental location, and then the resistivity change of the medium is obtained by reading the potential difference between the measured electrodes. In the experiment of resistivity to measure the pressure relief effect of hydraulic flushing, the experimental results obtained by different electrode arrangement are different, and the most electrode arrangement has not been developed yet, so the measurement results are unstable. Shen had applied electromagnetic radiation (EMR) technology to the evaluation of the outburst elimination effect of hydraulic flushing [12]. EMR signals are generated by the non-uniform charge migration caused by the deformation of coal and rock, while AE signals are generated by the release and propagation of elastic energy from within the material $[13,14]$. Compared with EMR technology, AE technology avoids the influence of charged equipment on experimental results. Besides, contact testing can better reflect the initial damage and damage evolution process of materials [15-18].

At present, reflecting changes in coal seam stress and gas pressure through real-time monitoring of acoustic emission (AE) signals generated during coal and rock fracturing has gradually become a common method for studying the dynamic instability process of coal and rock. Zhao [19] studied the precursor information of coal sample rupture and instability under the conditions of uniaxial and cyclic loading, finding that AE signals could be used as an effective precursor for water burst and coal and gas outburst. Tang [20] performed uniaxial compression experiments on water-bearing coal and dry coal and collected the AE signals at the same time. Then, changes in the frequency and amplitude of AE signals were analyzed after the signals were subjected to wavelet packet denoising. The results show that the AE signals of water-bearing coal and rock changed notably after wavelet packet denoising. Zhang [21] measured the AE signals of coal samples under cyclic loading, proving that there was a good positive correlation between AE parameters and stress. Huang [22] carried out uniaxial compression tests on different groups of coal and rock and adopted the change in $\mathrm{AE}$ 
signals to reflect the stress variation. Feng [23] analyzed the effects of gas pressure and confining pressure on common coal, gas-bearing coal and gas-bearing coal and rock by measuring their $\mathrm{AE}$ signals during unloading. Sirdesai [24] observed the development of micro-cracks in fine grained Dholpur sandstone that had been thermally treated under uniaxial compression, and he used the changes in AE signals to reflect the evolution process of mechanical properties. The above researches suggest that $\mathrm{AE}$ has become a common technical means in the study on the deformation and fracturing of coal and rock [25]. Therefore, it is of great significance for promoting safe production of mines to conduct an in-depth study on characteristics of AE signals in the process of hydraulic flushing and then explore a technology for testing outburst elimination effect of hydraulic flushing based on the characteristics of AE signals. There are a few new methods to evaluate the pressure relief effect of hydraulic flushing, and AE is a widely used new method to study the fracture process of coal and rock. Based on the above analysis, we first put forward using AE signal changes to test the pressure relief and anti-reflection effect of hydraulic flushing. First laboratory experiments were conducted to monitor the variation of AE signals during the hydraulic flushing in real time, in order to reflect the condition of fractures around the coal seam borehole. Then the changes in stress and gas drainage concentration around the borehole were simultaneously measured in the field experiment, to test the effects of pressure relief and permeability enhancement of the coal seam.

\section{Experimental Process}

\subsection{Apparatus}

As shown in Figure 1, the experimental system consists of a uniaxial compression test system, a hydraulic flushing system and an AE signal acquisition system. The uniaxial compression test system, which is composed of a Press, a DCS (Data Collection System) and a Power Test V3.3 control program, is an electro-hydraulic servo pressure-testing machine controlled by the SANS computer. It can realize uniform loading by the modes of force control and displacement control. The hydraulic flushing system, which consists of a D999 high-pressure pump, a high-pressure water pipe, a water pressure gauge and an orifice-sealing device, can pressurize the water and flush the high-pressure water into the simulated coal seam through the water pipe. The AE signal acquisition system is the CAT- 1 type AE data acquisition system produced by Physical Acoustics Company of the United States. The system can simultaneously acquire the data transmitted through 8 channels at a high speed. To avoid noise interference, the experiment was carried out in the AFGP-II high efficiency shielding room.

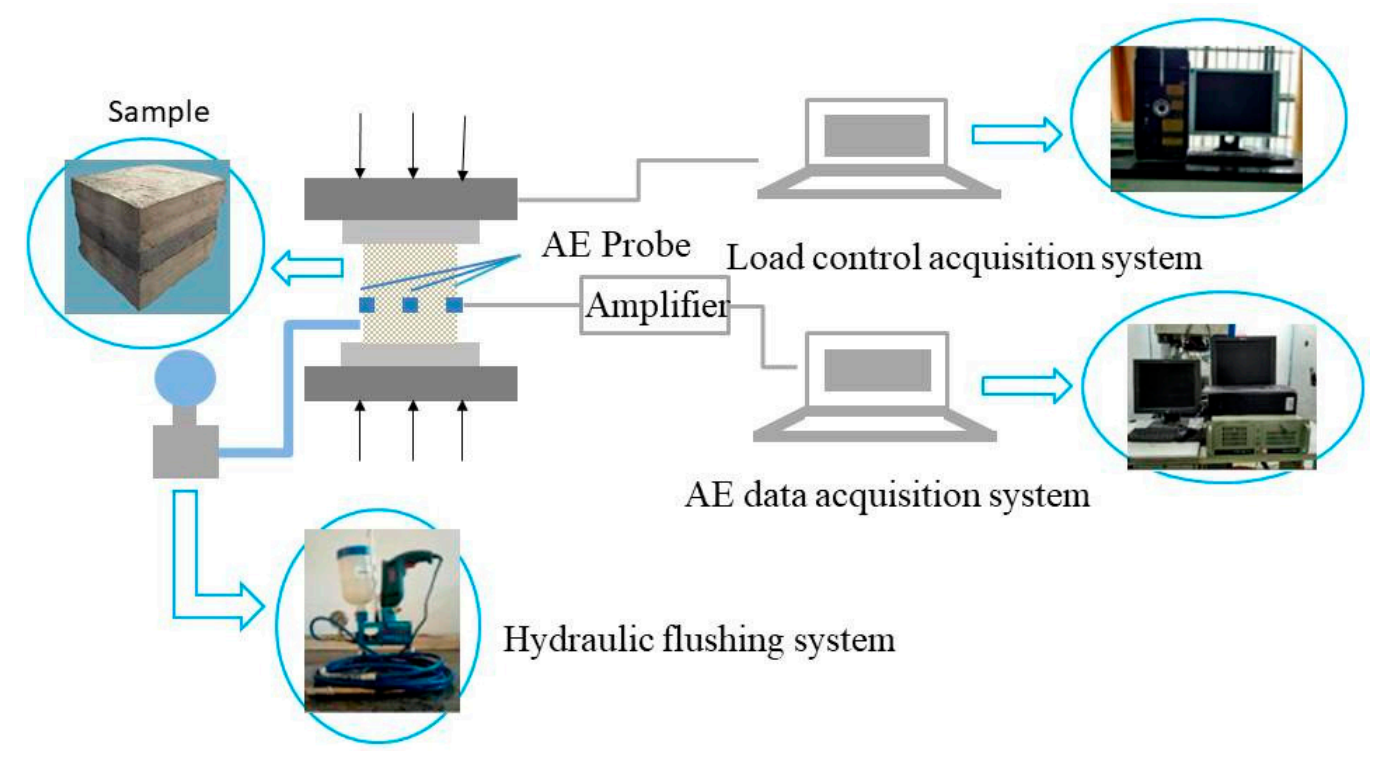

Figure 1. Apparatus. 


\subsection{Experimental Model}

Based on the geological structure of the mine, the following experimental models were designed to simulate changes in AE signals during the hydraulic flushing. The models were $45 \mathrm{~cm} \times 39 \mathrm{~cm} \times$ $48 \mathrm{~cm}$ (high $\times$ wide $\times$ depth) cubes consisting of five layers in total, simulating the basic roof, the direct roof, the coal seam, the direct bottom and the basic bottom. They were made from calcium carbonate, cement, gypsum and fly ash according to the ratios listed in Table 1 . In addition, a $2 \mathrm{~cm} \times 10 \mathrm{~cm}$ circular borehole was reserved in the middle of the coal seam for conducting the flushing. Two models were prepared in total, as presented in Figure 2.

Table 1. The ingredients of the models.

\begin{tabular}{ccc}
\hline Rock Number & Rock Name & Calcium Carbonate: Cement: Gypsum: Fly Ash \\
\hline 1 & Basic roof & $2: 1: 1: 1$ \\
2 & Direct roof & $1: 1: 1: 1$ \\
3 & Coal seam & $10: 1: 5: 8$ \\
4 & Direct bottom & $1: 1: 1: 1$ \\
5 & Basic bottom & $2: 1: 1: 1$ \\
\hline
\end{tabular}

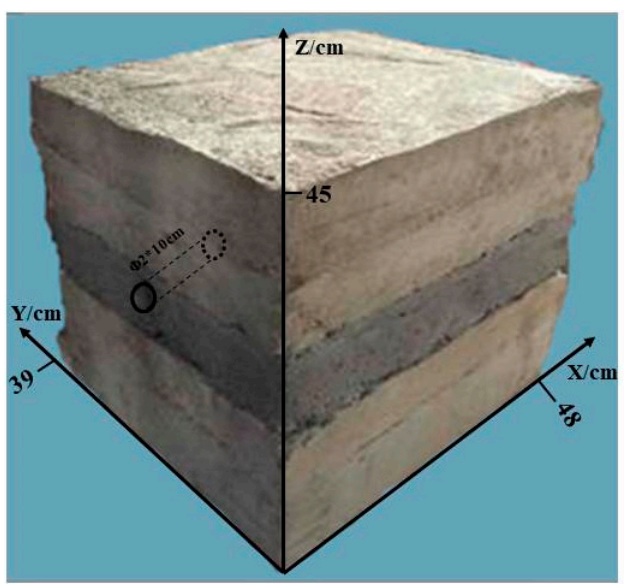

Figure 2. Physical diagram of the experimental model.

\subsection{Experimental Method}

The pre-made model 1 was placed on the test bench. Six AE probes were placed around the coal seam and connected to the CAT- 1 host. The pump was filled with water, and a $5 \mathrm{~mm}$ steel nozzle was connected to the outlet. A container was placed under the test bench to collect water and debris during flushing. The specific procedure of the experiment is as follows. (1) The first step was to set the loading scheme: The system applied load to the model at a rate of $200 \mathrm{~N} / \mathrm{s}$ and kept the displacement unchanged when the load reached $10 \mathrm{kN}$;(2) With parameters such as the threshold value and maximum value of the CAT-1 AE signal acquisition system debugged, the signal acquisition system and loading system were turned on to collect the data. The data were acquired for another $60 \mathrm{~s}$ after the pressure remained unchanged; (3) The water injection pump was turned on to perform hydraulic flushing until load of the loading system was reduced to $3 \mathrm{kN}$. Next, the water pump and pressing machine were turned off. During this period, the AE signals were continuously collected; (4) Relevant data were saved after the completion of the above experiment on Model 1, after which Steps (1)-(3) were repeated on Model 2. The water pump was turned on to flush Model 2 until the amount of its debris approximated that of Model 1. Afterwards, the data were acquired for another $60 \mathrm{~s}$; (5) The data were recorded and the laboratory was cleaned at the end of the experiment. 


\section{Experimental Results}

\subsection{Analysis of Experimental Results}

The changes in load and water pressure recorded during the hydraulic flushing are exhibited in Figure 3. The load continues to rise at the beginning of the experiment, reaching the peak of $10 \mathrm{kN}$ at $65 \mathrm{~s}$, after which the load remains unchanged. Since the hydraulic flushing starts at $125 \mathrm{~s}$, the load gradually decreases with the rise of water pressure. The process of hydraulic flushing can be divided into three stages. The first stage is the non-cross-flow stage. From $125 \mathrm{~s}$ onwards, the fluid particle of water jet contacts the coal surface, during which the fluid particle and the coal particle undergo intense energy and momentum exchange, resulting in a rapid rise of water pressure and a gradual decline of load. As the water pressure reaches about $4.65 \mathrm{MPa}$ by $165 \mathrm{~s}$, a large amount of debris in the model is flushed out, providing sufficient space for the internal deformation of the coal. The second stage is the steady flow stage. From $165 \mathrm{~s}$ to $375 \mathrm{~s}$, the energy carried by fluid particles are transferred to the coal after the contact between fluid particles and the coal. As a result, with their own energy reduced, the water jet is subjected to the compression effect caused by the subsequent particles, and a compression wave is formed on the jet axis, so that the jet boundary expands laterally. Meanwhile, the pressure on the coal surface gradually falls from the initial high pressure to the stable pressure of the water jet. The water pressure fluctuates within a certain range, and the debris continues to be flushed out. The third stage is the unloading stage where the impact of water on the coal is gradually weakened. The water pump is turned off, and the flushing is completed. As the water pressure drops rapidly, the load on the coal is continuously reduced until it becomes stable.

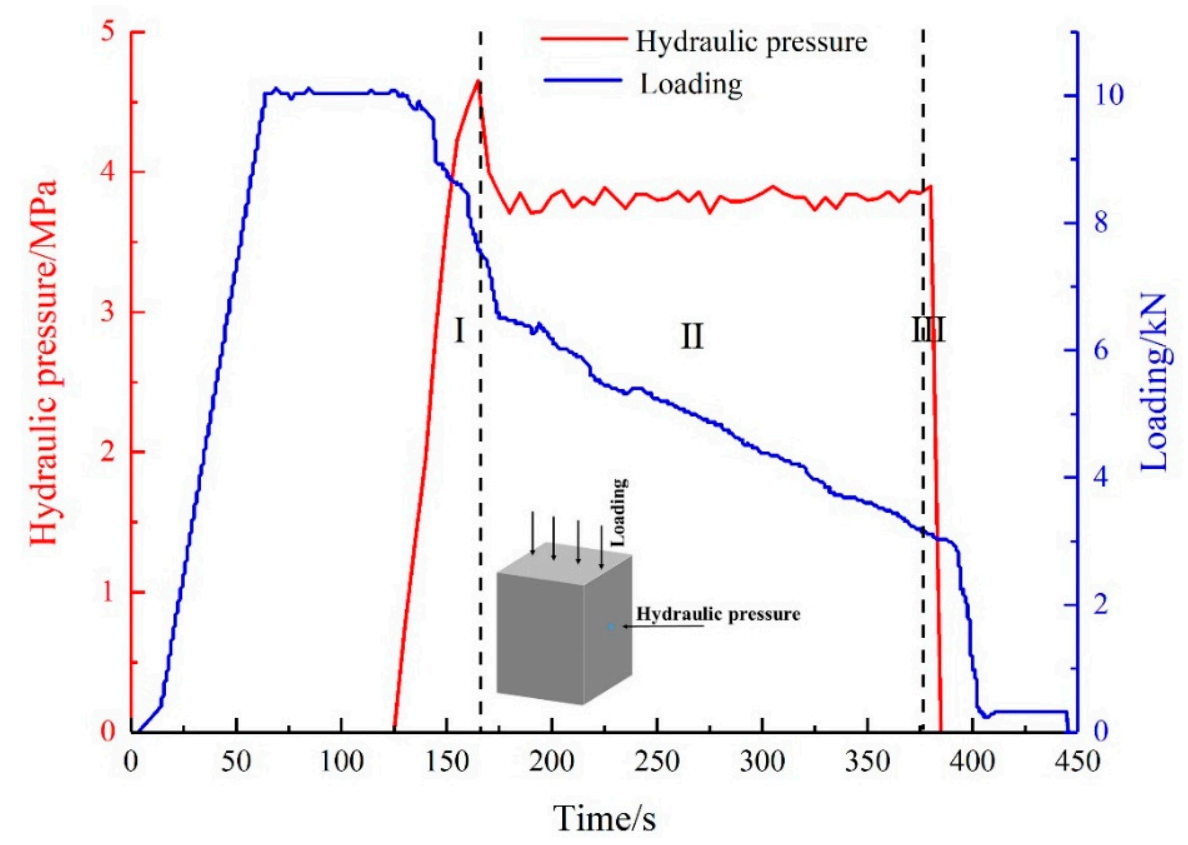

Figure 3. Hydraulic pressure and loading changes in the experiment process.

AE signals are generated in the process of deformation and fracturing of coal or rock. Since the signals are generated by strain energy released by elastic waves within coal and rock, their counts and intensity can both qualitatively reflect the degree of coal and rock damage [25]. AE signals of Models 1 and 2 collected during the hydraulic flushing are illustrated in Figure 4. Overall, AE signals of the two models change in basically the same pattern. Taking Model 1 as an example, AE signals collected during the hydraulic flushing are analyzed. 


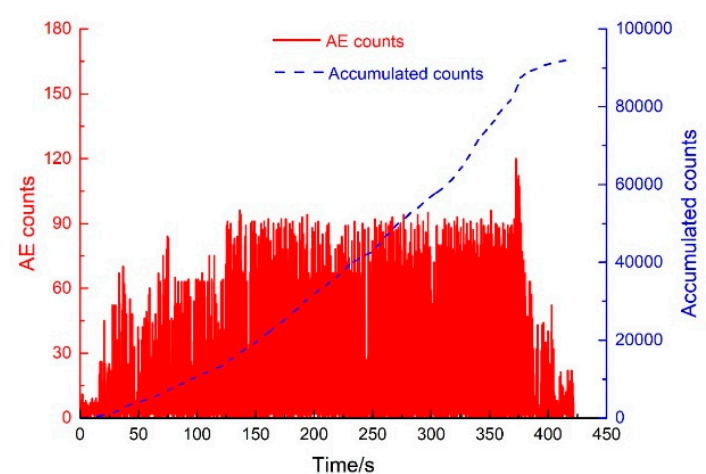

(a) AE counts of Model 1

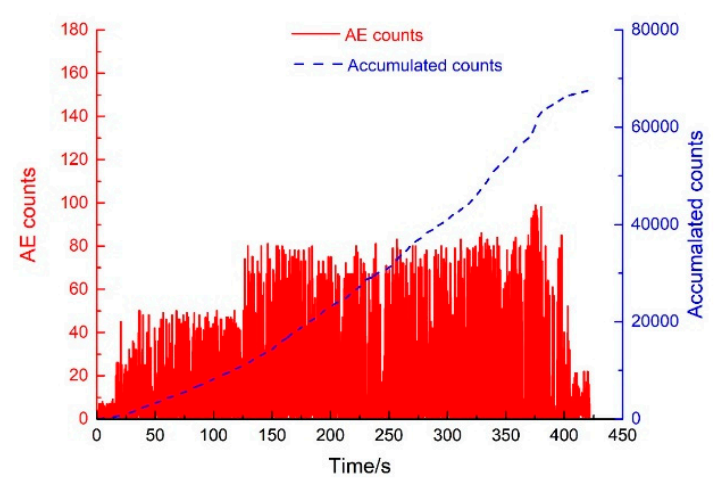

(c) AE counts of Model 2

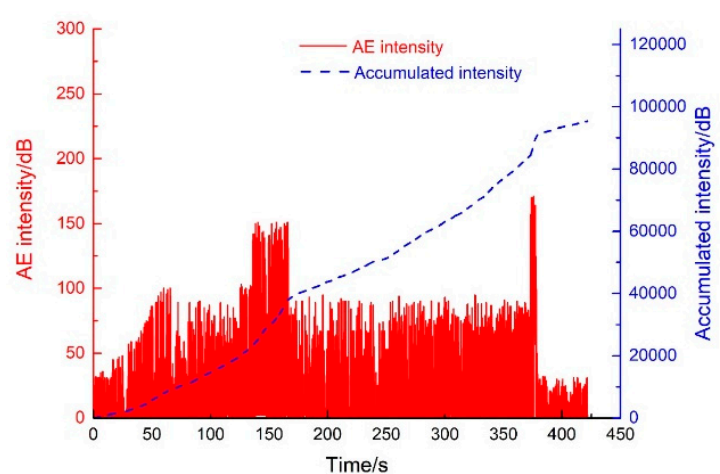

(b) AE intensity of Model 1

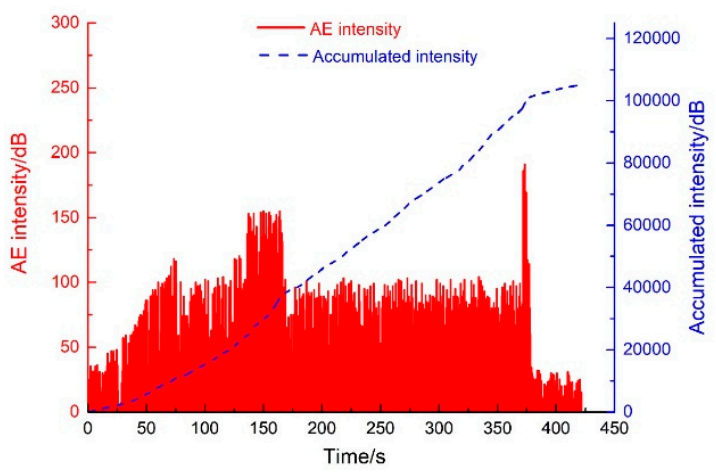

(d) AE intensity of Model 2

Figure 4. AE counts and intensity changes during hydraulic flushing.

In the experiment, the $\mathrm{AE}$ counts show a trend of step-shaped change while the AE intensity exhibits a trend of M-shaped change. Before $65 \mathrm{~s}$, the AE signals rise as the load increases. From 65-125 s, the load on the model remains unchanged, so AE counts and intensity remain basically stable, fluctuating at around 50 and $95 \mathrm{~dB}$, respectively. In the range of $0-125 \mathrm{~s}$, the model stays in the linear elastic phase where the curves of cumulative $\mathrm{AE}$ counts and cumulative $\mathrm{AE}$ intensity both rise steadily. It can be seen that the changes in AE can reflect the compaction of fractures in the loading process. As hydraulic flushing begins at $125 \mathrm{~s}$, the water pressure quickly jumps to about $4.6 \mathrm{MPa}$, and meanwhile the load begins to decrease. Accordingly, AE counts suddenly increase to about 87, and the $\mathrm{AE}$ intensity grows again to $100 \mathrm{~dB}$. During the first $10 \mathrm{~s}$ of flushing, the debris is slowly flushed out from the model, and AE signals change slightly. From $135 \mathrm{~s}$ to $165 \mathrm{~s}$, the AE intensity begins to increase to 130-150 dB. During this period, the water pressure falls notably, and cracks within the model begin to expand. Afterwards, as the flushing proceeds, a large amount of debris continues to be flushed out, and the water flow penetrates into previous micro-cracks, so that the cracks continue to expand and connect to form large fractures. At around $375 \mathrm{~s}$, the flushing is completed, and the water pressure drops rapidly. At this time, AE counts suddenly rise to about 93; AE intensity also reaches a peak of $170 \mathrm{~dB}$; and the slopes of curves of $\mathrm{AE}$ cumulative counts and $\mathrm{AE}$ cumulative intensity increase slightly. Then, the experiment is over. AE counts are reduced to below 20, and $\mathrm{AE}$ intensity fluctuates at around $30 \mathrm{~dB}$.

From the above analysis, it can be concluded that the AE counts and intensity vary with the load on the model, reaching the peak at the end of flushing and decreasing to a stable range after the relief of pressure. The $\mathrm{AE}$ counts and intensity are reduced by $60 \%$ and $68 \%$ respectively after the pressure of models is completely relieved. Therefore, the changes in AE counts and intensity can reflect the process of hydraulic flushing experiment and provide experimental basis for later field test. 


\subsection{Relationship between AE Signals and Coal and Rock Damage}

AE signals are generated by coal and rock fracturing under load. In the process of hydraulic flushing, the process and mechanism of coal and rock deformation and fracturing is an important research orientation. Mogi [26] studied the characteristics of AE signals during rock fracturing under compression and proposed four stages of AE evolution. Yang and Jing [27] carried out uniaxial compression experiments on brittle sandstone samples with a single fracture to study the fracture and crack evolution process of sandstone. The experimental results correspond well with AE signals. Kong [28] carried out uniaxial compression experiments on coal samples with original cracks and recorded the changes in $\mathrm{AE}$ counts and cumulative counts during the experimental process. Furthermore, he quantitatively calculated the damage variables based on the damage theory.

Coal generates stress and strain under load. Assuming that the coal is intact before loading, that is, the damage variable is 0 , the damage variable can be defined as $[29,30]$ :

$$
D=A_{i} / \mathrm{A}
$$

where $A_{i}$ is the damage area at the time $i$; $\mathrm{A}$ is the total cross-sectional area of the model; $D$ is the damage variable. When the non-destructed Section $\mathrm{A}$ is completely destroyed, the AE counts generated is denoted as $\mathrm{N}_{0}$. Then, the $\mathrm{AE}$ counts generated by the destruction of a unit area can be expressed as $N$ :

$$
\mathrm{N}=\mathrm{N}_{0} / \mathrm{A}
$$

when the damage area reaches $A_{i}$, the $\mathrm{AE}$ counts generated can be expressed as:

$$
N_{i}=\mathrm{N}_{0} A_{i} / \mathrm{A}
$$

The damage variable can be obtained by substituting Equation (3) into Equation (1):

$$
D=N_{i} / \mathrm{N}_{0}
$$

The damage variable and its variation with time are obtained by substituting laboratory experimental data into Equation (4), as shown in Figure 5.

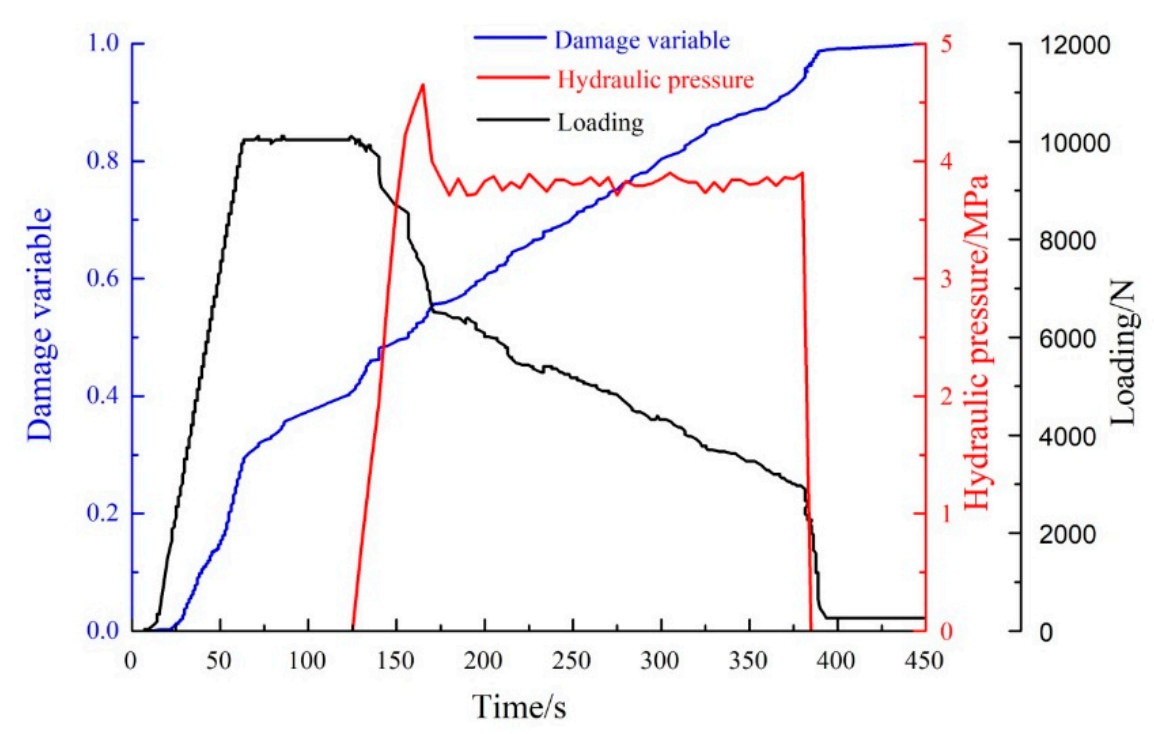

Figure 5. Synchronous analysis of damage variable, hydraulic pressure and loading changes with time.

In the initial stage of loading, the value of damage variable grows with the increase of load. After $65 \mathrm{~s}$, the load stabilizes at $10 \mathrm{kN}$. Due to the action of load in the early stage, the original cracks 
in coal are gradually compacted and closed, during which the value of damage variable grows at a reduced rate. As the hydraulic flushing experiment starts at $125 \mathrm{~s}$, the water enters the coal to wet, adsorb and diffuse inside the coal, resulting in changes in the coal and rock structure and the emergence, expansion and connection of micro-cracks. As the water pressure rises, more fractures appear around the borehole, allowing water to enter the deep part of the coal. As a result, the water pressure in pores rises; fractures continue to expand; and the value of damage variable continues to grow. The flushing ends at $375 \mathrm{~s}$. With the sudden drops of load and water pressure, fractures within the coal develop rapidly; the value of damage variable continues to increase to 1 until the end of the flushing; and the coal around the borehole is destroyed. Therefore, the damage variable D of the coal during the hydraulic flushing, which directly reflects the degree of dynamic fracturing damage, can be solved by AE counts. In light of this, this study proposes a new method for evaluating the pressure relief effect of coal seam hydraulic flushing based on the changes of AE signals.

\section{Discussion}

In the above section, AE signals generated in the process of coal seam hydraulic flushing were tested under laboratory conditions, based on which, the characteristics of parameters were analyzed. The characteristics of AE signals obtained during the flushing simulation can be used to reflect the effect of hydraulic flushing. In order to verify the experimental results further, the hydraulic flushing process and AE signals before and after flushing in Liangbei Coal Mine, Yuzhou City, China were monitored using the safe multi-channel AE data acquisition system of YDD16 intrinsically coal and rock dynamic hazard monitoring device for mines. Moreover, their characteristics and laws were analyzed. The characteristics of AE signals were compared with monitoring indicators of conventional dynamic hazard, and the response law of AE signals in hydraulic flushing process was analyzed.

\subsection{Field Experiment Methods and Procedure}

The YDD16 mine intrinsically safe coal and rock dynamic hazard monitoring device for mines developed by China University of Mining and Technology was used in the field experiment, as shown in Figure 6. The experimental site is the bottom extraction roadway of 21011 working face of Liangbei Coal Mine of Shenhuo Group.

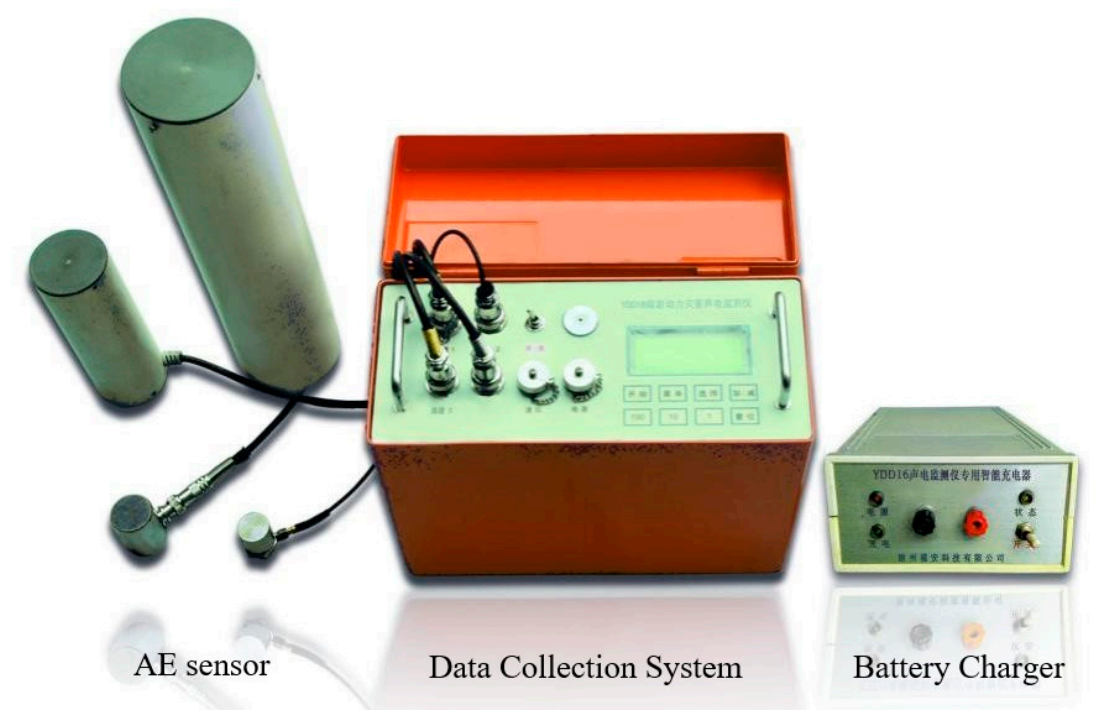

Figure 6. Field test equipment of AE.

In the experimental section of bottom extraction roadway of 21011 working face, the thickness, the dip angle and buried depth of the coal seam are $4.9 \mathrm{~m}, 12.3^{\circ}$ and $543-622 \mathrm{~m}$, respectively. In addition, the thickness of rock pillar between the coal seam and the roadway is $19 \mathrm{~m}$. A total of five boreholes 
were arranged in the experiment, namely, the hydraulic flushing borehole e, the AE signal testing boreholes $\mathrm{a}$ and $\mathrm{b}$, the gas drainage borehole 1 , and the stress monitoring borehole 2 , as presented in Figure 7. An AE probe was arranged within each of the two AE boreholes. The experimental steps are as follows: First, the boreholes were constructed, with the height of hydraulic flushing borehole being $7 \mathrm{~m}$. Second, the AE probes were connected Channels 1 and 2 of YDD16 and fixed within the AE testing boreholes with the aid of a fixing device. Third, YDD16 was turned on to set the main parameters, and the pressure of flushing water should not exceed $15 \mathrm{MPa}$. Forth, after the AE background value was tested for $120 \mathrm{~s}$, the AE signals were tested at five periods (flushing for $5 \mathrm{~min}$, flushing for $1 \mathrm{~h}, 1 \mathrm{~h}$ after flushing, $3 \mathrm{~h}$ after flushing and $24 \mathrm{~h}$ after flushing) for $120 \mathrm{~s}$ each. Fifth, the data were processed, that is, characteristics of AE signal variation of hydraulic flushing were analyzed.

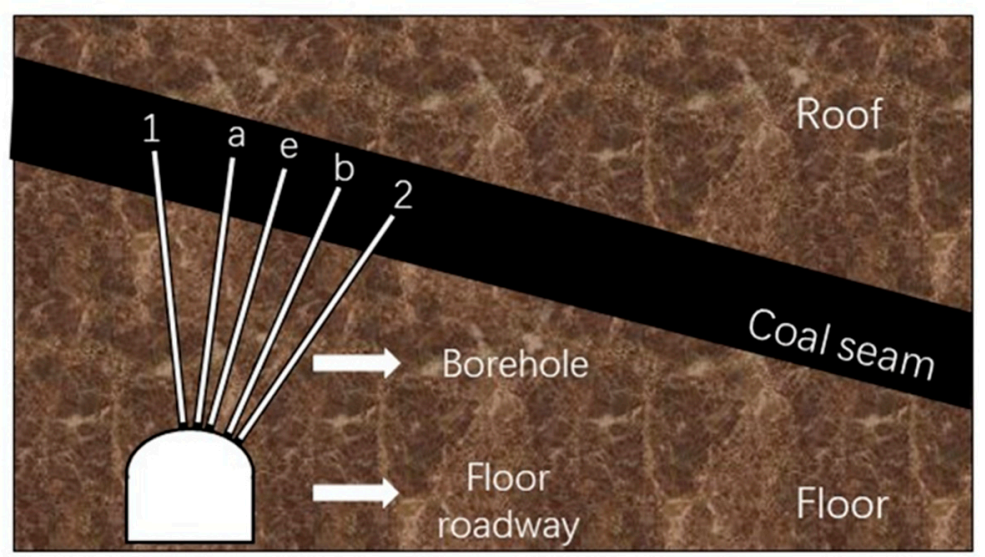

Figure 7. Borehole layout in field test.

\subsection{Analysis of Experimental Results}

The hydraulic flushing lasts for $2.5 \mathrm{~h}$. The AE signals were monitored before hydraulic flushing, flushing for $5 \mathrm{~min}$, flushing for $1 \mathrm{~h}, 1 \mathrm{~h}$ after flushing, $3 \mathrm{~h}$ after flushing and $24 \mathrm{~h}$ after flushing for 120 s each.

The test result of AE borehole a is analyzed as an example. As shown in Figure 8, before the flushing, the coal and rock remains in a relatively stable state, with AE counts and intensity being 20 and $28 \mathrm{~dB}$, respectively. After the flushing is carried out for $5 \mathrm{~min}$, its stable state is destroyed under the action of water pressure. In this stage, micro-cracks begin to appear within the coal and rock, and AE counts and intensity start to rise. After the flushing proceeds for $1 \mathrm{~h}$, the mechanical properties of coal decrease under the action of hydraulic power, accompanied by the appearance of macro-cracks. In this stage, the AE signals reach a peak, with AE counts and intensity being about 105 and $94 \mathrm{~dB}$, respectively. After the flushing is completed, the coal around the borehole expands and deforms, and the stress shifts to a deep position. As a result, the AE signals gradually decrease. After the flushing has been completed for $24 \mathrm{~h}$, both the stress around the coal and the AE signals tend to stabilize, but AE counts and intensity are both larger than the values before the flushing. In general, AE counts and intensity gradually increase during the flushing, reaching a maximum after flushing for $1 \mathrm{~h}$. Then, with the continuous change in coal seam structure and the gradual drop of stress, AE counts and intensity gradually decrease and tend to stabilize.

The above analysis suggests that the AE signals change with the change in coal expansion and fracturing. The more serious the crack expansion and coal seam fracturing are, the greater the $\mathrm{AE}$ signals are. In addition, after the pressure of coal seam is relieved, AE counts and intensity are smaller than the ones before hydraulic flushing. 


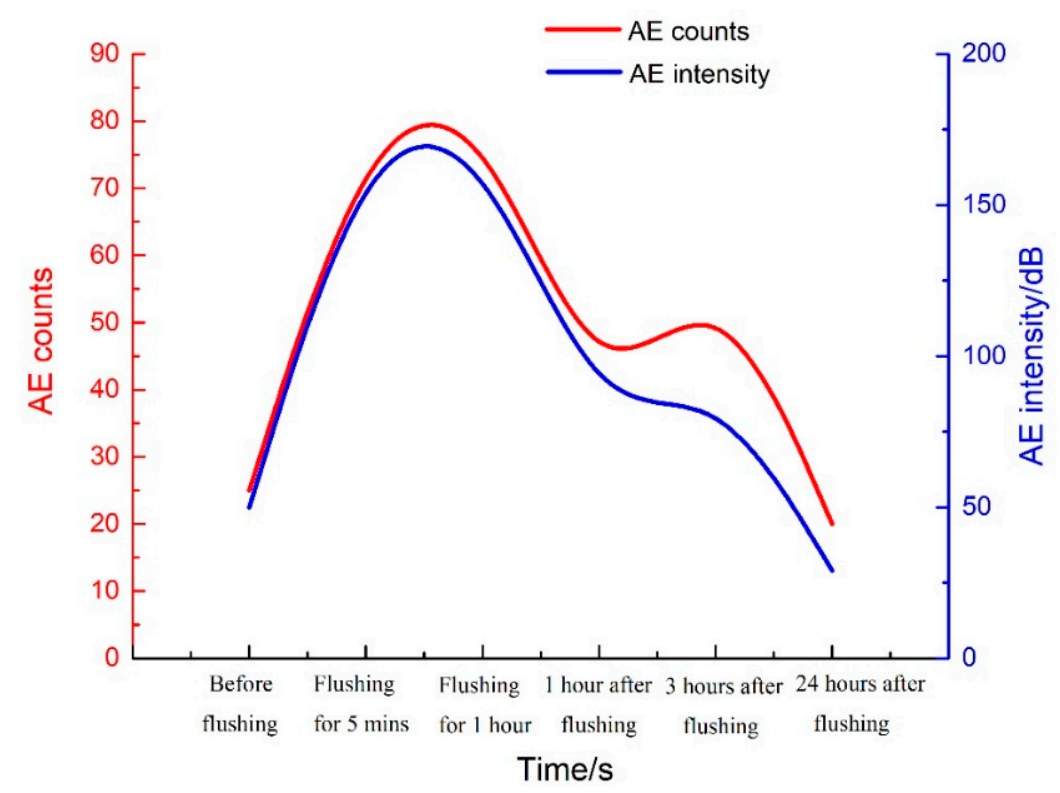

Figure 8. AE signals changes in different stages of hydraulic flushing.

\subsection{Analysis of Gas Concentration and Coal Seam Stress before and after Hydraulic Flushing}

To verify the effect of $\mathrm{AE}$ signal evaluation on hydraulic flushing, the gas drainage concentration and the coal seam stress are used as contrast indicators of AE test for hydraulic flushing and outburst elimination effects. As illustrated in Figure 9, the process of hydraulic flushing can be divided into three stages: Before the start of flushing, during hydraulic flushing and after the end of flushing. In the first stage, the coal seam stress remains basically stable, fluctuating at around $3.25 \mathrm{MPa}$; the concentration of gas drainage lies at $6.08 \%$ which is relatively low. In the second stage, the stress declines slowly while the gas concentration rises gradually, indicating that the internal expansion, slip and other forms of deformation lead to the drop of stress and the desorption of gas as the hydraulic flushing proceeds. As the flushing goes on for about $1 \mathrm{~h}$, the stress is still relatively stable, but the gas drainage concentration begins to jump rapidly. At this moment, changes in AE signals gradually reach the peak. In the third stage, after the flushing has been completed for 1-3 $h$, the stress is transferred to the deep part of the coal, so the coal seam stress begins to drop rapidly. Due to the large burial depth of the coal seam, the gas pressure in coal pores is greatly affected by the ground stress. The release of the ground stress enables a large amount of gas to desorb, so that the concentration of gas drainage continues to rise. Afterwards, the stress continues to drop to $2.0 \mathrm{MPa}$ while the gas concentration rises to $20.51 \%$. Then, the stress drops at a gradually reduced rate while the gas concentration keeps fluctuating at around $20 \%$. This indicates that the internal coal undergoes significant deformation after the end of flushing. The stress gradually stabilizes through constant adjustment, which is characterized by the continuous relief of coal seam pressure and the basic completion of gas desorption. After the flushing has been completed for $24 \mathrm{~h}$, the stress slowly stabilizes at 1.24 MPa, suggesting that the internal structure and stress of the coal have stabilized. Compared with the data before the flushing, the internal stress of the coal seam decreases by $61.8 \%$ and the concentration of gas drainage within the borehole almost triples after the flushing, proving that hydraulic flushing is an effective technology for outburst elimination. 


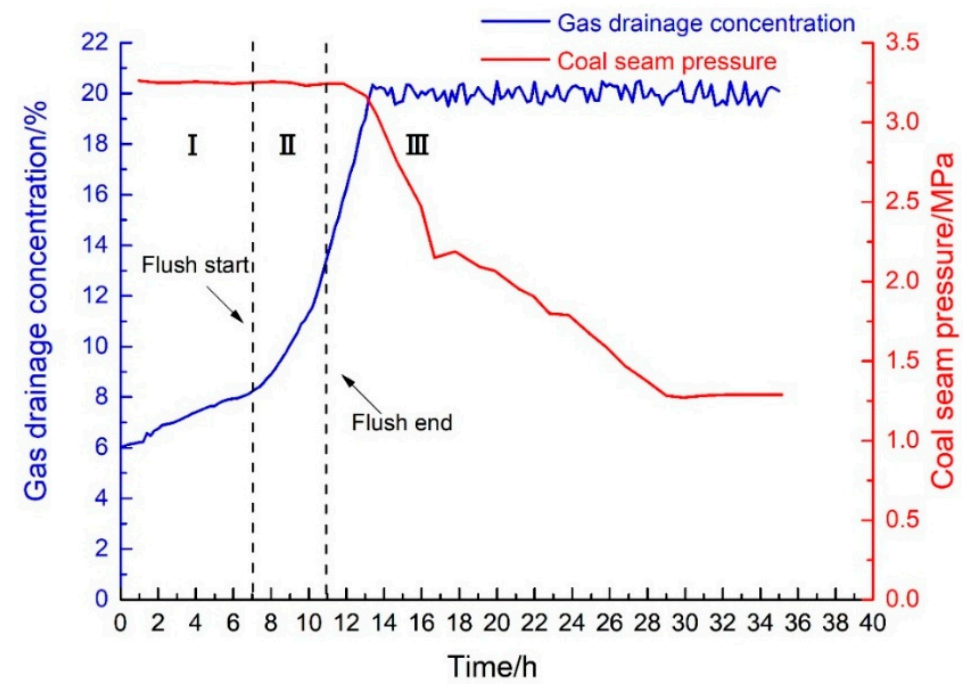

Figure 9. Changes in gas drainage concentration and coal seam stress.

\subsection{Change in Coal Stress during Hydraulic Flushing}

In fact, hydraulic flushing refers to process in which a high-pressure water jet impacts the coal to enlarge and expand the borehole in the coal seam. Figure 10, obtained using the RFPA ${ }^{2 \mathrm{D}}$ software for analyzing rock fracturing, exhibits the changes in coal and rock fracturing during hydraulic flushing. In the figure, the black area is the borehole, and the blue area is the stress change. Changes in stress distribution around the borehole with hydraulic the flushing can be observed from Figure 10.
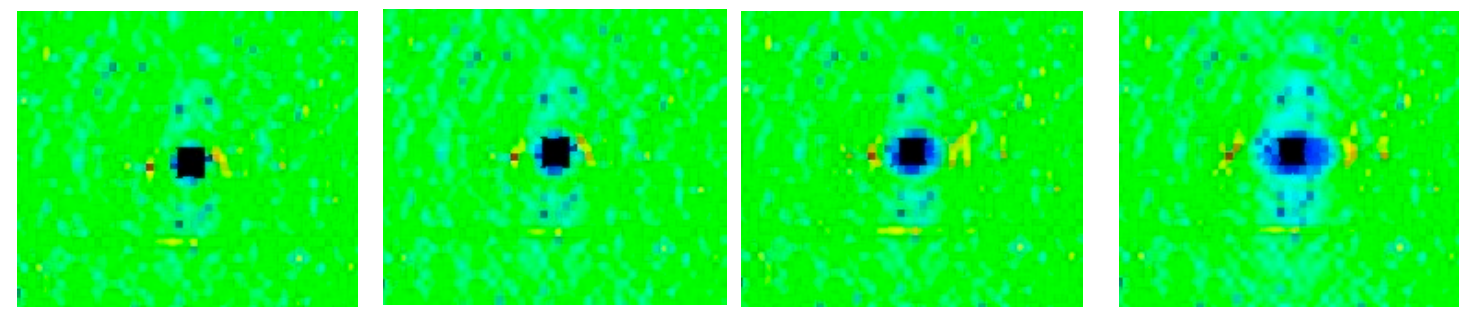

Figure 10. Simulation results of damage evolution of coal and rock.

Figure 11 shows the stress distribution after the completion of flushing. Due to the existence of the borehole, the stress is redistributed, concentrating around the borehole. In the primary stress area, the hoop stress $\sigma_{\theta}$ gradually increases while the radial stress $\sigma_{\mathrm{r}}$ decreases. Within the elastic area, as the stress difference gradually grows, the coal is compacted, and the permeability gradually falls to the lowest value. The coal near the borehole stays in the plastic area where the coal undergoes plastic deformation and fracturing because it fails to bear huge concentrated stress. The stress of coal near the borehole is lower than that of the primary stress area. Moreover, because of the connection and expansion of fractures, the permeability gradually increases until the permeability of borehole wall reaches a peak and exceeds that of the primary stress area. The results reveal that hydraulic flushing technology can remarkably enhance coal seam permeability and lower coal seam stress. In addition, the changes in AE signals during the hydraulic flushing can be employed to reasonably determine the range of pressure relief. The research results are helpful to guide the field application.

Considering the different mechanical properties of coal and rock in different mines and the different conditions of gas occurrence, the AE characteristics of the coal seam before and after hydraulic flushing are also different. Therefore, this method still needs to be further verified and improved. In addition, the time-domain signal of $\mathrm{AE}$ is selected for analysis in this paper. The frequency domain signal of AE has not been discussed, and the frequency domain signal of the acoustic emission also contains a lot of effective information, which is also the direction of our future research. 


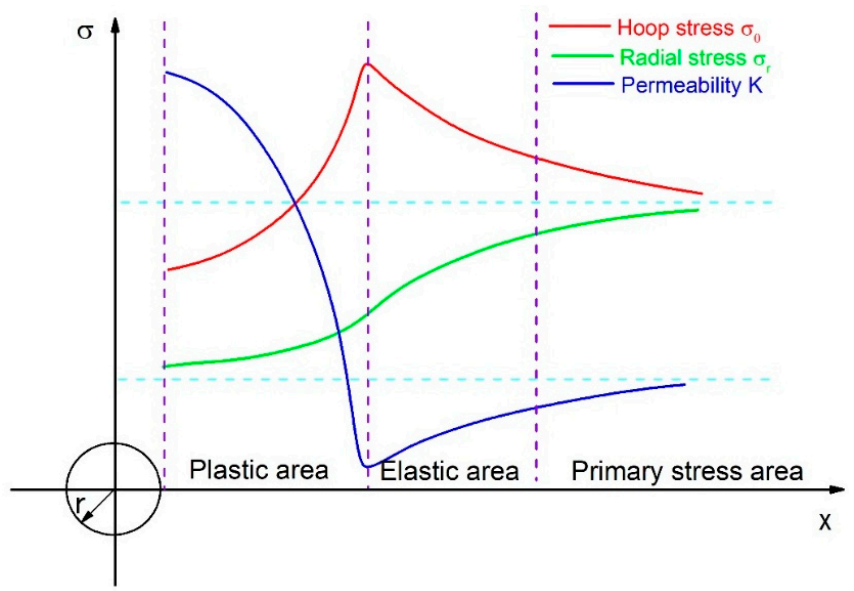

Figure 11. Stress distribution around the bore hole after hydraulic flushing.

\section{Conclusions}

In this study, a new method for evaluating the coal seam outburst elimination effect using hydraulic flushing by AE signals was proposed, and the feasibility of this method was verified by combining laboratory experiments with field applications. The main conclusions are drawn as follows:

(1) The experimental results indicate that $\mathrm{AE}$ signals can be detected in the whole hydraulic flushing process. In the elastic stage, AE signals increase with the rise of the load. In the stable load stage, the fractures are compacted, so AE signals change little. After the hydraulic flushing begins, the changes in $\mathrm{AE}$ signals are greatly affected by the change in hydraulic pressure. At the end of flushing, AE counts and intensity both reach the peak values.

(2) In the process of hydraulic flushing, the coal undergoes fracturing and deformation under the action of high-pressure water jet, and the elastic energy is released and transmitted within the coal, thus generating AE signals. The more obvious the coal and rock fracturing and deformation is caused by hydraulic impact, the greater the AE counts and intensity are. In the process of hydraulic flushing, the damage variable keeps growing at a rate corresponding to the coal stress.

(3) In the field experiment of hydraulic flushing, the deformation of coal around the borehole is the most serious after the flushing has been completed for 1-3 $\mathrm{h}$. In this stage, the AE intensity reaches the maximum value; the stress of the coal seam around the borehole diffuses far away, which is consistent with the simulation results; and the concentration of gas drainage keeps rising. After the flushing has been completed for $24 \mathrm{~h}$, the internal structure and stress of the coal seam tend to stabilize, and AE counts and intensity also gradually decrease and tend to be stable. After the completion of the field experiment, the AE intensity and the coal seam stress are reduced by $54 \%$ and $61 \%$, respectively, while the gas drainage concentration triples, proving the remarkable pressure relief and permeability enhancement effects of hydraulic flushing.

Author Contributions: Conceptualization, R.S. and X.Z.; Data curation, X.Z.; Formal analysis, E.W. and H.L.; Resources, E.W.; Supervision, X.H. and Z.H.

Funding: This research is supported by the Fundamental Research Funds for the Central Universities, grant number 2019XKQYMS55.

Conflicts of Interest: The authors declare no conflict of interest.

\section{References}

1. Mark, C. Coal bursts that occur during development: A rock mechanics enigma. Int. J. Min. Sci. Technol. 2018, 28, 35-42. [CrossRef]

2. Wang, Z.; Sun, X.; Tingkan, L.U.; Han, Y. Experiment research on strengthening gas drainage effect with fracturing technique by liquid CO_2 phase transition. J. Henan Polytech. Univ. 2015, 34, 1-5. 
3. Ge, Z.; Mei, X.; Jia, Y.; Lu, Y.; Xia, B. Influence radius of slotted borehole drainage by high pressure water jet. J. Min. Saf. Eng. 2014, 31, 657-664.

4. Wei, J.; Li, B.; Wang, K.; Sun, D. 3D numerical simulation of boreholes for gas drainage based on the pore-fracture dual media. Int. J. Min. Sci. Technol. 2016, 26, 739-744. [CrossRef]

5. Qiu, L.; Song, D.; Wang, E.; Liu, Z.; Shen, R.; Li, D.; Jia, H.; Hong, S. Determination of hydraulic flushing impact range by DC resistivity test method. Int. J. Rock Mech. Min. Sci. 2018, 107, 127-135. [CrossRef]

6. Bo, L.; Liu, M.; Liu, Y.; Wang, N.; Guo, X. Research on pressure relief scope of hydraulic flushing bore hole. Procedia Eng. 2011, 26, 382-387. [CrossRef]

7. Lin, B.; Ju, Q.; Shen, C.; Xu, Y.; Dai, H.; Yang, W. Investigation on highly effective depressurization property of dual-power drilling and its application. J. China Coal Soc. 2013, 38, 911-917.

8. Zhang, H.; Cheng, Y.; Liu, Q.; Yuan, L.; Dong, J.; Wang, L.; Qi, Y.; Wang, W. A novel in-seam borehole hydraulic flushing gas extraction technology in the heading face: Enhanced permeability mechanism, gas flow characteristics, and application. J. Nat. Gas Sci. Eng. 2017, 46, 498-514. [CrossRef]

9. Kong, B.; Wang, E.; Li, Z.; Wang, X.; Liu, X.; Nan, L.; Yang, Y. Electromagnetic radiation characteristics and mechanical properties of deformed and fractured sandstone after high temperature treatment. Eng. Geol. 2016, 209, 82-92. [CrossRef]

10. Zhao, Y.; Lin, B.; Liu, T.; Li, Q.; Kong, J. Gas Flow Field Evolution around Hydraulic Slotted Borehole in Anisotropic Coal. J. Nat. Gas Sci. Eng. 2018, 58, 189-200. [CrossRef]

11. Li, D. Hydraulic drill hole reaming technology with large flow and draining of coal mine gas. Int. J. Min. Sci. Technol. 2018. Available online: https://www.sciencedirect.com/science/article/pii/S2095268617304251 (accessed on 25 April 2019). [CrossRef]

12. Shen, R.; Qiu, L.; Lv, G.; Wang, E.; Li, H.; Xu, H.; Xuan, Z.; Hou, Z. An effect evaluation method of coal seam hydraulic flushing by EMR. J. Nat. Gas Sci. Eng. 2018, 54, 154-162. [CrossRef]

13. Vishal, V.; Ranjith, P.G.; Singh, T.N. An experimental investigation on behaviour of coal under fluid saturation, using acoustic emission. J. Nat. Gas Sci. Eng. 2015, 22, 428-436. [CrossRef]

14. Yang, Y.; Wang, D.; Guo, M.; Bo, L.I. Study of rock damage characteristics based on Acoustic Emission test under triaxial compression. Chin. J. Rock Mech. Eng. 2014, 33, 98-104.

15. He, X.; Chen, W.; Nie, B.; Ming, Z. Classification technique for danger classes of coal and gas outburst in deep coal mines. Saf. Sci. 2010, 48, 173-178. [CrossRef]

16. He, M.; Miao, J.; Feng, J. Rock burst process of limestone and its acoustic emission characteristics under true-triaxial unloading conditions. Int. J. Rock Mech. Min. Sci. 2010, 47, 286-298. [CrossRef]

17. Liang, Y.; Li, Q.; Gu, Y.; Zou, Q. Mechanical and acoustic emission characteristics of rock: Effect of loading and unloading confining pressure at the postpeak stage. J. Nat. Gas Sci. Eng. 2017, 44, 54-64. [CrossRef]

18. Mastrogiannis, D.; Antsygina, T.N.; Chishko, K.A.; Mavromatou, C.; Hadjicontis, V. Relationship between electromagnetic and acoustic emissions in deformed piezoelectric media: Microcracking signals. Int. J. Solids Struct. 2015, 56-57, 118-125. [CrossRef]

19. Zhao, Y.; Jiang, Y. Acoustic emission and thermal infrared precursors associated with bump-prone coal failure. Int. J. Coal Geol. 2010, 83, 11-20. [CrossRef]

20. Tang, S.; Tong, M.; Hu, J.; He, X. Characteristics of acoustic emission signals in damp cracking coal rocks. Min. Sci. Technol. (China) 2010, 20, 143-147. [CrossRef]

21. Zhang, Z.; Wang, E.; Nan, L.; Li, X.; Wang, X.; Li, Z. Damage evolution analysis of coal samples under cyclic loading based on single-link cluster method. J. Appl. Geophys. 2018, 152, 56-64. [CrossRef]

22. Huang, B.; Liu, J. The effect of loading rate on the behavior of samples composed of coal and rock. Int. J. Rock Mech. Min. Sci. 2013, 61, 23-30. [CrossRef]

23. Feng, D.; Kai, W.; Wang, G.; Jiang, Y.; Xin, C.; Xiang, Z. Investigation on acoustic emission characteristics during deformation and failure of gas-bearing coal-rock combined bodies. J. Loss Prev. Process Ind. 2018, 55, 253-266.

24. Sirdesai, N.N.; Gupta, T.; Singh, T.N.; Ranjith, P.G. Studying the acoustic emission response of an Indian monumental sandstone under varying temperatures and strains. Constr. Build. Mater. 2018, 168, 346-361. [CrossRef]

25. Zhang, Z.; Wang, E.; Chen, D.; Li, X.; Li, N. The observation of AE events under uniaxial compression and the quantitative relationship between the anisotropy index and the main failure plane. J. Appl. Geophys. 2016, 134, 183-190. [CrossRef] 
26. Mogi, K. Study of Elastic Shocks Caused by the Fracture of Heterogeneous Materials and its Relations to Earthquake Phenomena. Bull. Earthq. Res. Inst. 1962, 40, 125-173.

27. Yang, S.; Jing, H. Strength failure and crack coalescence behavior of brittle sandstone samples containing a single fissure under uniaxial compression. Int. J. Fract. 2011, 168, 227-250. [CrossRef]

28. Kong, X.; Wang, E.; He, X.; Zhao, E.; Zhao, C. Mechanical Characteristics and Dynamic Damage Evolution Mechanism of Coal samples in Compressive Loading Experiments. Eng. Fract. Mech. 2018, 210, 160-169. [CrossRef]

29. Kachanov, L.M. Rupture Time Under Creep Conditions. Int. J. Fract. 1999, 97, 11-18. [CrossRef]

30. Liu, B.; Huang, J.; Wang, Z.; Liu, L. Study on damage evolution and Acoustic Emission character of coal-rock under uniaxial compression. Chin. J. Rock Mech. Eng. 2009, 28, 3234-3238.

(C) 2019 by the authors. Licensee MDPI, Basel, Switzerland. This article is an open access article distributed under the terms and conditions of the Creative Commons Attribution (CC BY) license (http://creativecommons.org/licenses/by/4.0/). 